\title{
(-)-Epicatechin and the colonic 2,3-dihydroxybenzoic acid metabolite regulate glucose uptake, glucose production, and improve insulin signalling in renal NRK-52E cells
}

\author{
David Álvarez Cilleros ${ }^{1}$, María Ángeles Martín ${ }^{1,2}$ and Sonia Ramos ${ }^{1, *}$ \\ ${ }^{1}$ Department of Metabolism and Nutrition \\ Institute of Food Science and Technology and Nutrition (ICTAN) \\ Consejo Superior de Investigaciones Científicas (CSIC) \\ José Antonio Novais 10 \\ Ciudad Universitaria, 28040, Madrid \\ Spain
}

Phone: +34.91.544.56.07

Fax: +34.91.549.36.27

${ }^{2}$ Centro de Investigación Biomédica en Red de Diabetes y Enfermedades Metabólicas Asociadas (CIBERDEM), ISCIII, Spain.

* Corresponding author: e-mail: s.ramos@ictan.csic.es

Abbreviations used: AKT/PKB, protein kinase B; DHBA, 2,3-dihydroxybenzoic acid; DHPAA, 3,4-dihydroxyphenylacetic acid; EC, (-)-epicatechin; FBS, foetal bovine serum; GLUT-2, glucose transporter-2; GS, glycogen synthase; GSK-3, glycogen synthase kinase-3; G6Pase, glucose-6-phosphatase; HPPA, 3-hydroxyphenilpropionic acid; IR, insulin receptor; IRS, insulin receptor substrate; PEPCK, phosphoenolpyruvate carboxykinase; PI3K, phosphatidylinositol-3-kinase; SGLT-2, sodium-glucose cotransporter-2, VA, vanillic acid.

Keywords: Epicatechin and colonic metabolites, Glucose production, Glucose uptake, Insulin signalling pathway, NRK-52E cells. 


\begin{abstract}
Scope: (-)-Epicatechin (EC) and main colonic phenolic acids derived from flavonoid intake, such as 2,3-dihydroxybenzoic acid (DHBA), 3,4-dihydroxyphenylacetic acid (DHPAA), 3-hydroxyphenylpropionic acid (HPPA), and vanillic acid (VA), have been suggested to exert beneficial effects in diabetes, although the mechanism for their actions remains unknown. In this study, the modulation of glucose homeostasis and insulin signalling by the mentioned compounds on renal proximal tubular NRK-52E cells was investigated.
\end{abstract}

Methods and results: Levels of the glucose transporters SGLT-2 and GLUT-2, as well as glucose uptake, glucose production, and key proteins of the insulin pathways, namely insulin receptor (IR), insulin receptor substrate-1 (IRS-1), and PI3K/AKT pathway were analysed. EC $(5-20 \mu \mathrm{M})$ and DHBA $(20 \mu \mathrm{M})$ reduced both renal glucose uptake and production. Interestingly, EC and DHBA did not modify the levels of SGLT-2 and GLUT-2, and modulated the expression of phosphoenolpyruvate carboxykinase via AKT leading to a diminished glucose production. EC and DHBA also enhanced the tyrosine phosphorylated and total IR and IRS-1 levels, and activated the PI3K/AKT pathway in NRK-52E cells.

Conclusion: EC and DHBA regulate the renal glucose homeostasis by modulating both glucose uptake and production, and strengthen the insulin signalling by activating key proteins of that pathway in NRK-52E cells. 


\section{Introduction}

Diabetes nephropathy is a major complication of diabetes and a leading cause of endstage renal disease [1]. Chronic hyperglycaemia is associated with tubule-interstitial changes that accompany progressive renal dysfunction [1, 2]; indeed, renal glucose reabsorption has been considered to have a pathophysiological role in diabetes [1]. Therefore, a long-term reduction in hyperglycaemia is an important treatment in preventing nephropathy.

Kidneys play a major role in glucose homeostasis. The main site for glucose reabsorption is the early S1 segment of the proximal tubule and this process is largely mediated by the high-capacity transporter sodium-glucose co-transporter-2 (SGLT-2) [2]. In this regard, inhibitors of SGLT-2 have been demonstrated to increase glycosuria and reduce hyperglycaemia in type 2 diabetes $[3,4]$. Importantly, the gluconeogenesis is a differentiated function of the renal cortex that also contributes to the glucose homeostasis, as well as to the insulin modulatory effects [2]. In diabetes, there is a marked increase in renal glucose uptake, which might be accompanied by the upregulation of SGLT-2 and glucose transporter-2 (GLUT-2) levels, and the renal gluconeogenesis is enhanced because of the deregulation of rate-limiting gluconeogenic enzymes $[2,4,5]$. Additionally, defects at the insulin signalling are thought to affect the renal glucose homeostasis and, therefore, to contribute to the hyperglycaemia [4]. Consequently, treatments aimed at improving glucose homeostasis in renal cells are considered critical for optimal management of diabetes type 2 and to prevent, retard or treat associated renal complications.

Flavanols, such as (-)-epicatechin (EC), are a group of polyphenols abundant in cocoa, grapes, tea, and many other fruit and vegetables [6, 7] with demonstrated health beneficial effects, including antidiabetic properties [7, 8]. However, it should be 
considered that their health effects depend on their bioavailability [7, 9]. Thus, monomers are readily absorbed in the small intestine, but oligomers and polymers are metabolized in the colon by the intestinal microbiota into different phenolic acids of low molecular weight $[7,9]$. These microbial metabolites are further absorbed and circulate in the body prior to their excretion in urine, and represent a very large percentage of the amount ingested. Accordingly, food polyphenols and microbial-derived metabolites should be taken into account when assessing the impact of polyphenols on health. In this regard, mono- and di-hydroxylated phenylpropionic and phenylacetic acids have been found as main colonic phenolic acids derived from flavanol intake [9], and, similarly to the monomer EC, exhibit potential health beneficial effects $[7,9,10]$. EC and some colonic polyphenolic metabolites were able to exert insulin-like activities [1012], counteract key features of diabetic complications [13, 14], improve insulin sensitivity $[15,16]$, as well as blood glucose levels $[13,17]$ and protect the functionality of insulin-sensitive tissues in diabetes [10, 15-19]. However, to the best of our knowledge, whether EC and the microbial phenolic metabolites derived from flavanol intake have an effect on renal tubular cells is unclear, and the precise mechanism for their potential preventive activities related to glucose metabolism and insulin signalling in the kidney has not been studied.

The aim of this study is to evaluate the effects of EC and the colonic-derived flavonoid metabolites 2,3-dihydroxybenzoic acid (DHBA), 3,4-dihydroxyphenylacetic acid (DHPAA), 3-hydroxyphenylpropionic acid (HPPA), and vanillic acid (VA) on key modulatory mechanisms related to the glucose homeostasis in renal proximal tubular NRK-52E cells, including glucose uptake, glucose production and insulin signalling pathways. 


\section{Materials and methods}

\subsection{Materials and chemicals}

(-)-EC ( $>95 \%$ of purity), DHBA ( $\geq 99 \%$ of purity), DHPAA ( $>98 \%$ of purity), HPPA (>98\% of purity), VA (>97\% of purity), LY294002 (2-(4-morpholinyl)-8-phenyl-1(4H)benzopyran-4-one hydrochloride), phlorizin, anti-mouse IgG-agarose and sodium lactate were purchased from Sigma Chemical (Madrid, Spain). The fluorescent probe Dglucose, 2-deoxy-2-((7-nitro-2,1,3-benzoxadiazol-4-yl)amino) (2-NBDG) was from Molecular Probes (Invitrogen, Madrid, Spain). Anti-protein kinase B (AKT) and antiphospho-Ser473-AKT detecting levels of phospho- and total AKT, anti-glycogen synthase kinase-3 $\alpha / \beta$ (GSK3) and anti-phospho-GSK3 $\alpha / \beta$ recognizing phosphorylated Ser21/9 of GSK3, as well as anti-glycogen synthase (GS) and anti-phospho-GS recognizing phosphorylated Ser641 of GS, and anti- $\beta$-actin were obtained from Cell Signalling Technology (Izasa, Madrid, Spain). Anti-insulin receptor- $\beta$ (IR $\beta$ ), antiSGLT-2, anti-phosphoenolpyruvate carboxykinase (PEPCK) and anti-Tyr(P) (PY20) were purchased from Santa Cruz (sc-711, sc-98975, sc-32879 and sc-508, respectively, Qimigen, Madrid, Spain). Anti-insulin receptor substrate-1 (IRS-1) and anti-GLUT-2 were from Millipore (Madrid, Spain). Materials and chemicals for electrophoresis were from BioRad (BioRad Laboratories S.A., Madrid, Spain). Cell culture dishes, glutamine and cell culture medium were from Falcon (Cajal, Madrid, Spain) and Lonza (Madrid, Spain), respectively.

\subsection{Cell culture and treatments}

Rat NRK-52E cells (kindly provided by Prof. Dr. Patricio Aller, Centro de Investigaciones Biológicas, CSIC, Madrid, Spain) were grown in DMEM medium 
containing 5.5 mM D-glucose, $2 \mathrm{mM}$ glutamine, supplemented with $10 \%$ foetal bovine serum (FBS). Cells were maintained at $37^{\circ} \mathrm{C}$ in a humidified atmosphere of $5 \% \mathrm{CO}_{2}$. Cells were treated with different concentrations of EC, DHBA, DHPAA, HPPA or VA $(1-20 \mu \mathrm{M})$ diluted in serum-free culture medium with $5.5 \mathrm{mM}$ D-glucose and $2 \mathrm{mM}$ glutamine during $24 \mathrm{~h}$. In the experiments with the inhibitors, cells were preincubated with $20 \mu \mathrm{M}$ LY294002 or $0.5 \mathrm{mM}$ phlorizin for $1 \mathrm{~h}$ prior to $24 \mathrm{~h}$ of EC or DHBA treatment.

\subsection{Cell viability assay}

Cell viability was determined by using the crystal violet assay [12]. NRK-52E cells were seeded at low density ( $10^{4}$ cells per well) in 96-well plates, grown for $20 \mathrm{~h}$ and incubated with crystal violet $(0.2 \%$ in ethanol) for $20 \mathrm{~min}$. Plates were rinsed with water, allowed to dry, and $1 \%$ sodium dodecylsulfate was added. The absorbance of each well was measured using a microplate reader at $570 \mathrm{~nm}$.

\subsection{Glucose uptake}

Cellular glucose uptake was quantified by the 2-NBDG assay using a microplate reader. Cells were plated in 24 -well plates at a rate of $2 \times 10^{5}$ cells per well and after the treatments, 2-NBDG was added at $10 \mu \mathrm{M}$ final concentration and incubated for $1 \mathrm{~h}$ at $37^{\circ} \mathrm{C}$. Then, cells were washed twice with PBS, serum-free medium was added and the fluorescence intensity immediately measured in a microplate reader at an excitation wavelength of $485 \mathrm{~nm}$ and an emission wavelength of $530 \mathrm{~nm}$. After being taken by the cells, 2-NBDG was converted into a non-fluorescent derivative (2-NBDG metabolite). A fair estimation of the overall glucose uptake was obtained by quantifying the diminution in the fluorescence. The assay has been described elsewhere [19, 20]. 


\subsection{Glucose production assay}

NRK-52E cells were seeded in 24 -well plates $\left(2 \times 10^{5}\right.$ cells per well) and after the treatment, the medium was replaced with glucose production buffer consisting of glucose-free DMEM (pH 7.4) without phenol red (Invitrogen, Madrid, Spain), supplemented with $5 \mathrm{mM}$ sodium lactate and $5 \mathrm{mM}$ glutamine, as previously described $[12,21,22]$. After $1.5 \mathrm{~h}$ of incubation, medium was collected and the glucose concentration measured with a colorimetric glucose assay kit (Sigma, Madrid, Spain). The readings were then normalized to the total protein content determined from the whole-cell lysates.

\subsection{Preparation of cell lysates}

Cells were lysed at $4^{\circ} \mathrm{C}$ in a buffer containing $25 \mathrm{mM}$ HEPES (pH 7.5), $0.3 \mathrm{M} \mathrm{NaCl}, 1.5$ $\mathrm{mM} \mathrm{MgCl}_{2}, 0.2 \mathrm{mM}$ EDTA, $0.5 \mathrm{mM}$ dithiothreitol, $0.1 \%$ Trition X-100, $200 \mathrm{mM} \beta-$ glycerolphosphate, $\quad 0.1 \quad \mathrm{mM} \quad \mathrm{Na}_{3} \mathrm{VO}_{4}, \quad 2 \mu \mathrm{g} / \mathrm{mL}$ leupeptin and $1 \mathrm{mM}$ phenylmethylsulfonyl fluoride. The supernatants were collected, assayed for protein concentration by using the Bio-Rad (Bio-Rad, Madrid, Spain) protein assay kit according to the manufacture's specifications, aliquoted and stored at $-80^{\circ} \mathrm{C}$ until used for immunoprecipitation and/or Western blot analyses.

\subsection{Immunoprecipitation}

Protein extracts containing $200 \mu \mathrm{g}$ of protein were immunoprecipitated overnight at $4^{\circ} \mathrm{C}$ with gentle rotation in the presence of $2-5 \mu \mathrm{g}$ of anti-Tyr(P) (PY20) antibody, followed by the addition of anti-mouse IgG-agarose. After mixing for $2 \mathrm{~h}$, the pellets were 
collected by centrifugation, and the supernatants were discarded. Then, the pellets were washed and saved for Western blot analyses.

\subsection{Western blot analysis}

Equal amounts of proteins were separated by SDS-polyacrylamide gel electrophoresis and transferred to polyvinylidene difluoride filters (Bio-Rad, Madrid, Spain). Membranes were probed with the corresponding primary antibody followed by incubation with peroxide-conjugated anti-rabbit (GE Healthcare, Madrid, Spain) or antimouse (Sigma, Madrid, Spain) immunoglobulin. Blots were developed with the ECL system (GE Healthcare, Madrid, Spain). Normalization of Western blot was ensured by $\beta$-actin and bands were quantified using a scanner and accompanying software.

\subsection{Statistics}

Prior to statistical analysis, data were tested for homogeneity of variances by the test of Levene; for multiple comparisons, one-way ANOVA was followed by the Bonferroni test when variances were homogeneous or by the Tamhane test when variances were not homogeneous. $P<0.05$ was considered significant. A SPSS version 23.0 program has been used. 


\section{Results}

\subsection{Effects of EC and colonic phenolic metabolites on cell viability}

To discard the potential toxic effects of EC, DHBA, DHPAA, HPPA, and VA on a renal tubular cell line (NRK-52E), cells were exposed to a range of concentrations (1-100 $\mu \mathrm{M})$ for $24 \mathrm{~h}$.

Treatment of NRK-52E cells for $24 \mathrm{~h}$ with EC or any of the mentioned microbial phenolic metabolites did not evoke changes in cell viability, as determined by the crystal violet assay, indicating that the concentrations selected for the study did not damage cell integrity during the period of incubation (Supplementary Table 1). Therefore, the lowest and realistic range of concentrations was selected for further studies [12].

\subsection{Effects of EC and colonic phenolic metabolites on glucose uptake and glucose production}

To investigate whether the exposure of renal tubular cells to EC or colonic phenolic metabolites can modulate both glucose uptake and production, NRK-52E cells were incubated with 1-20 $\mu \mathrm{M}$ of EC, DHBA, DHPAA, HPPA, or VA for $24 \mathrm{~h}$.

As shown in Table 1, treatment of cells with EC and DHBA, but not with DHPAA, HPPA, or VA, decreased the glucose production. Similarly, the glucose uptake was reduced (as indicated by the increase in the percentage of 2-NDBG uptake) after incubating the cells with EC and DHBA, but not with DHPAA, HPPA, or VA. The mentioned diminution in both parameters (glucose uptake and glucose production) was observed at 10-20 $\mu \mathrm{M}$ EC and $20 \mu \mathrm{M}$ DHBA, respectively. Then, for subsequent

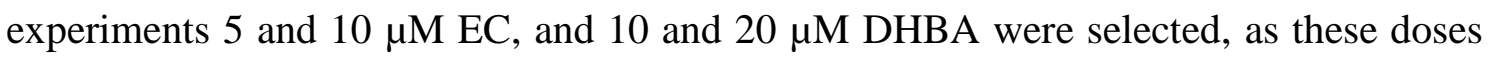


comprised the lowest concentrations of both compounds showing an effect on glucose uptake and production.

\subsection{Effects of EC and DHBA on glucose transporter protein levels}

Glucose uptake was modulated by EC and DHBA in NRK-52E cells, then the levels of the main glucose transporters in renal tubular cells were evaluated after incubating the cells with 5 and $10 \mu \mathrm{M}$ EC, and 10 and $20 \mu \mathrm{M}$ DHBA, respectively, for $24 \mathrm{~h}$. Treatment of NRK-52E cells with the concentrations selected for EC or DHBA did not affect the expression levels of SGLT-2 and GLUT-2 (Figure 1).

\subsection{Effect of EC and DHBA on PEPCK levels}

Because glucose production was diminished by EC and DHBA in NRK-52E cells, the expression levels of a major enzyme responsible of the regulation of gluconeogenesis, such as PEPCK, were analysed after $24 \mathrm{~h}$ EC- or DHBA-treatment.

EC or DHBA incubation decreased PEPCK levels, as illustrated in Figure 2. EC (10 $\mu \mathrm{M})$ induced the highest diminution in the levels of PEPCK in comparison to the other dose of EC $(P<0.05)$. DHBA equally reduced the levels of PEPCK at the highest concentration assayed $(P<0.05$, Figure 2$)$.

\subsection{Effects of EC and DHBA on tyrosine phosphorylation and protein levels of IR and its substrate IRS-1}

The modulation of IR and its downstream substrate IRS-1 is essential for maintaining the glucose homeostasis, and constitute the first steps for recruiting and activating downstream pathways [23, 24]. To test the effect of EC and DHBA on tyrosine 
phosphorylated and total levels of IR and IRS-1, NRK-52E cells were exposed for $24 \mathrm{~h}$ to the previously mentioned concentrations of these compounds.

As shown in Figure 3, IR and IRS-1 phosphorylated and total protein levels equally increased in the presence of the highest concentrations of EC and DHBA tested, that is $10 \mu \mathrm{M}$ and $20 \mu \mathrm{M}$, respectively $(P<0.05)$. However, the lowest doses of both compounds (5 $\mu \mathrm{M}$ EC and $10 \mu \mathrm{M}$ DHBA) seemed not to modify the levels of these proteins as they showed comparable values of phosphorylated and total IR and IRS-1 proteins to those of untreated cells.

\subsection{Effects of EC and DHBA on AKT, GSK3 and GS phosphorylation}

Following with the study of the insulin cascade, phosphorylated and total levels of AKT, GSK3 and GS were evaluated in cell lysates by Western blot. AKT facilitates glycogen synthesis, as its stimulation inhibits GSK-3 by phosphorylation, which subsequently phosphorylates and inactivates GS $[7,25]$.

EC and DHBA enhanced the phosphorylated levels of AKT and GSK3 at the highest dose used for each phenolic compound (Figures 4A-4C). In agreement with these results, $10 \mu \mathrm{M}$ EC and $20 \mu \mathrm{M}$ DHBA diminished the phosphorylated levels of GS (Figures 4A and 4D). There was no difference in the total levels of AKT, GSK3 and GS.

\subsection{Effect of EC and DHBA activation of AKT on gluconeogenesis}

Kidney produces glucose and some studies support the role of AKT in the repression of PEPCK [26]. In view of the increased levels of p-AKT induced by EC and DHBA, it was studied whether any of these substances were able to modulate the expression of PEPCK, and the production of glucose via AKT. To this end, NRK-52E cells were 
exposed to a selective inhibitor of AKT (LY294002) for $1 \mathrm{~h}$ followed by a-24 $\mathrm{h}$ incubation with EC or DHBA, and then the levels of PEPCK and the novo production of glucose were assayed. The concentrations selected for these analyses were the doses that clearly activated the AKT pathway, i.e. $10 \mu \mathrm{M}$ for EC and $20 \mu \mathrm{M}$ for DHBA.

Treatment of NRK-52E cells with EC or DHBA alone showed a comparable diminution in the expression of PEPCK $(P<0.05$, Figures 5A and 5B). LY294002 alone increased the levels of PEPCK, although these values decreased by the addition of EC and DHBA $(P<0.05$, Figures 5A and 5B). LY294002 treatment diminished p-AKT levels in all cells incubated with this inhibitor, although p-AKT values were partly recovered in the presence of EC or DHBA when compared to untreated cells $(P<0.05$, Figures 5A and 5C). In addition, the AKT selective inhibitor alone increased the glucose production, and this enhancement was less prominent in the cells treated with EC or DHBA and LY294002 (Figure 5D, $P<0.05$ ). Conversely, LY294002 could not totally block the inhibitory effect of EC and DHBA on PEPCK and glucose production $(P<0.05)$.

\subsection{Effect of EC and DHBA activation of SGLT-2 on glucose uptake}

SGLT-2 inhibitors are novel antidiabetic agents [3, 27], and phlorizin $(\mathrm{P})$ is a known SGLT-2 antagonist [28]. To compare the effects of EC or DHBA with P on the glucose uptake, SGLT-2 was inhibited by incubating the cells with $\mathrm{P}$ for $1 \mathrm{~h}$ prior to the treatment with EC or DHBA. As mentioned above, the concentrations selected for these analyses were the previously chosen $(10 \mu \mathrm{M}$ for $\mathrm{EC}$ and $20 \mu \mathrm{M}$ for DHBA), since they showed a prominent effect on the uptake of glucose.

As illustrated in Figure 6, treatment with P, EC or DHBA alone equally decreased the glucose uptake, that is, increased the percentage of 2-NBDG uptake in comparison to 
control cells $(P<0.05)$. Similar results were observed after the incubation with EC or DHBA when $\mathrm{P}$ was present $(P<0.05)$.

In diabetic patients, the glucose renal transport increases, and the levels of glucose transporters could be modulated [5, 29]. Then, levels of SGLT-2 and GLUT-2 were evaluated by Western blot. SGLT-2 and GLUT-2 expression levels remained unaltered after treating the cells with EC, DHBA and/or $\mathrm{P}(P<0.05$, Supplementary Figure 1$)$. All these results suggested that both natural compounds seem to exert the same effect as P. 


\section{Discussion}

Mounting evidence indicating that flavonoids might possess antidiabetic effects in animals and humans have been reported and these natural compounds have drawn attention because of their safety [7]. In this study, it has been demonstrated, for the first time, that EC and the colonic DHBA metabolite diminished the glucose uptake without affecting the levels of main glucose transporters in renal proximal tubular cells. It has also been shown that EC and DHBA enhanced the tyrosine phosphorylated and total IR and IRS-1 levels together with an activation of the PI3K/AKT pathway. In addition, EC and DHBA down-regulated the levels of the key gluconeogenic enzyme PEPCK and modulated the renal glucose production via AKT.

$\mathrm{EC}$ is the most abundant flavanol in cocoa, although it is also present in lower amounts in beverages and fruits, such as tea and grapes [7, 30]. After ingestion, a small amount of flavonoids is absorbed in the small intestine, but most of them are transformed in the colon into low-molecular-weight metabolites before absorption [9]. In fact, human studies have shown that the main urinary microbial phenolic acids derived from flavanol intake are mono- and di-hydroxylated phenylpropionic and phenylacetic acids, together with hydroxybenzoic acids [9]. In addition, it should be taken into account that pure compounds are accumulated in tissues as a consequence of a conjugationdeconjugation cycle [31]. Therefore, in the present work a pure compound and some of the most abundant compounds found in urine after the intake of flavanol-rich foods have been selected to study their effect on glucose uptake and glucose production, as well as on insulin signalling in renal proximal tubular cells [9]. Moreover, it is worth mentioning that the range of concentrations used in the study is not far from realistic. Indeed, concentrations ranging between 0.1-20 $\mu \mathrm{M}$ have been found in biological fluids 
after the intake of flavanols and they are considered within the range recommended for in vitro studies $[9,32]$.

Kidneys play an important role in glucose homeostasis via gluconeogenesis, glucose uptake from the circulation and glucose recovery from the urine [2]. Likewise, recent studies have suggested a role for the insulin signalling in the kidney on the modulation of glucose levels [24]. Currently, there are a wide range of antidiabetic agents, but many of them cannot achieve and maintain satisfactory glycaemic levels; thus, new agents are still in great demand. In this line, natural compounds, such as flavonoids, could play a major role, although little investigation at the molecular level has been performed.

In the renal proximal tubular cells, SGLT-2 reabsorbs approximately $90 \%$ of the filtered glucose, and the transcellular glucose transport is facilitated by GLUT-2 [2, 5]. In the present study, EC and DHBA did not show any effect on the protein levels of SGLT-2 and GLUT-2, and both substances diminished the glucose uptake. To the best of our knowledge, the influence of phenolic compounds on both transporters has not been evaluated in renal tubular cells previously, although it has been reported that in the renal proximal tubule GLUT-2 expression levels correlate with the glycaemia [2], and that GLUT-2 and SGLT-2 levels increase or remain unaltered in renal proximal tubular cells from diabetic patients [5, 29]; all this could explain the lack of effect of EC and DHBA on the levels of both transporters. Similarly, we have recently shown that EC did not modulate the protein levels of GLUT-2 in hepatic cells [12]. In addition, it should be mentioned that different natural products, including phlorizin and flavonoid enriched plant extracts, inhibit SGLT-2, which contributed to reduce the glycaemia [33]. In this line, our results could suggest that EC and DHBA could contribute to decrease the glucose uptake by inhibiting SGLT-2 without altering the expression of the glucose 
transporters, as described for dapagliflozin, empaglifozin, phlorizin or other natural products $[3,28,33,34]$.

Renal gluconeogenesis predominantly occurs in the proximal tubular cells $[2,4]$. Indeed, renal proximal tubular cells are particularly sensitive to the hyperglycaemia because the glucose uptake is insulin-independent [2, 4]. By contrast, insulin inhibits gluconeogenesis through the downregulation of gluconeogenic genes, being PEPCK one of the major enzymes responsible of the modulation of this process $[2,4]$. In the present work, EC and DHBA decreased PEPCK levels in NRK-52E cells. In agreement with our results, other natural compounds obtained from stem barks and roots, such as cinnamaldehyde and apocynin, reduced the glucose production and levels of this gluconeogenic enzyme in the kidney of diabetic animals $[35,36]$. Similarly, cocoa, tea, EC and other flavonoids such as naringenin and resveratrol have been reported to modulate the gluconeogenesis in different cultured cell lines and animal models of diabetes and obesity [16, 37-40].

An inhibited insulin signalling could lead to an enhanced gluconeogenesis, which could contribute to the hyperglycaemia [4]. The activation of IR-IRS-1 cascade initiates the stimulation of the PI3K/AKT pathway, which is needed for the metabolic effects of insulin and is responsible of the inhibition of GSK-3 and activation of GS. In this regard, EC and DHBA increased tyrosine phosphorylated and total levels of IR and IRS-1, as well as the phosphorylated values of AKT and GSK-3, and decreased p-GS levels in NRK-52E cells. In concert, polyphenols from Hibiscus sabdariffa diminished the inhibitory phosphorylated levels of (Ser307)-IRS-1 without modifying the total levels of this protein, as well as increased the values of p-PI3K in insulin-resistant renal proximal tubular cells [41]. In addition, in the kidney of fructose-fed rats quercetin and rutin restored the phosphorylated levels of IR, p-(Tyr)-IRS-1, and AKT, as well as 
reduced p-(Ser307)-IRS-1 values, whereas total levels of the mentioned proteins remained unchanged [42]. Correspondingly, in preadipocytes oligomeric structures of a grape-seed procyanidin extract activated IR by interacting with and inducing its tyrosine phosphorylation [43]. In this line, a down-regulation of IR and GSK3 has been reported in renal proximal tubules of diabetic rats [23], and a protective role for GSK3 has been suggested in high glucose-treated renal proximal tubular cells [44]. Moreover, it has been shown that the SGLT-2-mediated transport involved the phosphorylation of SGLT-2 via IR signalling in HEK-293T cells transfected with SGLT-1 and -2 [45], and in diabetic patients the administration of empagliflozin (an SGLT-2 inhibitor) improved insulin secretion and peripheral glucose uptake through poorly defined mechanisms [46]. Indeed, the contribution of the insulin-sensitizing effects to the overall beneficial effect of SGLT-2 inhibitory drugs needs to be examined. All together it might indicate that phenolic compounds reinforced the signal pathways responsive to insulin in NRK52E cultured cells.

Insulin signalling affects the renal gluconeogenesis in the proximal tubule, as mentioned $[4,24]$. AKT is a key protein of the insulin signalling pathway that has been suggested to play a role in the repression of PEPCK [47]. In agreement, here we have shown that AKT is involved in the modulation of PEPCK levels and the production of glucose in NRK-52E cells treated with EC and DHBA. As far as we know, the role of AKT induced by phenolic compounds on PEPCK and glucose production in renal tubular cells has not been studied previously. However, it has been demonstrated that AKT is involved in the inhibition of PEPCK and glucose production in hepatic cells treated with EC and clove extracts $[12,48]$. Additionally, it could be mentioned that some phenolic compounds have already demonstrated to prevent or ameliorate the induced-epithelialmesenchymal transition in proximal tubular renal cells and in kidneys of diabetic rats 
[41], as well as to contribute to preserve the renal function (including insulin pathway) in fructose-fed rats with renal injury [42]. Similarly, cocoa and EC have shown beneficial effects in different animal models of diabetes type 2 in different tissues such as liver and adipose tissue. Thus, the administration of a cocoa-rich diet to ZDF rats improved the liver insulin resistance by abolishing the increased p-(Ser)-IRS-1 levels and preventing the inactivation of the GSK3/GS pathway [37]. The hypoglycaemic effect of cocoa also appeared to be mediated through the decreased levels of hepatic PEPCK and by the increased values of glucokinase and GLUT-2. Likewise, an ECsupplemented diet alleviated insulin resistance in the liver and adipose tissue of highfructose fed rats by preventing partial or totally the decrease in the activation of key proteins of the insulin signalling pathway (IR, IRS1, AKT, and ERK1/2) [49].

In summary, EC and DHBA regulate glucose uptake and strengthen the insulin signalling pathway, as they enhanced tyrosine phosphorylated and total levels of IR and IRS-1, and activated the PI3K/AKT pathway. We have also revealed a new mechanism by which EC and DHBA modulate the renal gluconeogenesis and PEPCK expression via AKT in NRK-52E cultured cells. Further efforts are needed to define in detail the precise mechanism of action of EC and its colonic metabolites, such as DHBA, in the regulation of the glucose homeostasis and the insulin pathway in renal proximal tubular cells; especially in vivo studies will be helpful to ensure the potential benefits derived from their consumption in the prevention and/or treatment of type 2 diabetes complications before indicating any recommendation. 


\section{Acknowledgements}

This work was supported by the grants AGL2015-67087 (MINECO/FEDER, UE) and AGL2014-58205-REDC from the Spanish Ministry of Science and Innovation (MINECO). D. Álvarez-Cilleros is a FPI fellow from the predoctoral program of MINECO (BES-2016-076721).

\section{Conflict of interest statement}

The authors have declared no conflict of interest. 


\section{References}

[1] Forbes, J. M., Cooper, M. E., Mechanisms of diabetic complications. Physiol Rev. 2013, 93, 137-188.

[2] Mitrakou, A., Kidney: its impact on glucose homeostasis and hormonal regulation. Diabetes Res Clin Pract. 2011, 93S, S66-S72.

[3] Han, S., Hagan, D. L., Taylor, J. R., Xin, L., et al., Dapagliflozin, a selective SGLT2 inhibitor, improves glucose homeostasis in normal and diabetic rats. Diabetes. 2008, 57, 1723-1729.

[4] Artunc, F., Schleicher, E., Weigert, C., Fritsche, A., et al., The impact of insulin resistance on the kidney and vasculature. Nat Rev Nephrol. 2016, 12, 721-737.

[5] Rahmoune, H., Thompson, P. W., Ward, J. M., Smith, C. D., et al., Glucose transporters in human renal proximal tubular cells isolated from the urine of patients with non-insulin-dependent diabetes. Diabetes. 2005, 54, 3247-3234.

[6] Ramos, S., Cancer chemoprevention and chemotherapy: dietary polyphenols and signalling pathways. Mol Nutr Food Res. 2008, 52, 507-526.

[7] Martín, M. A., Goya, L., Ramos, S., Antidiabetic actions of cocoa flavanols. Mol Nutr Food Res. 2016, 60, 1756-1769.

[8] Babu, P. V. A., Liu, D., Gilbert, E. R., Recent advances in understanding the antidiabetic actions of dietary flavonoids. J Nutr Biochem. 2013, 24, 1777-1789.

[9] Monagas, M., Urpi-Sarda, M., Sanchez-Patan, F., Llorach, R., et al., Insights into the metabolism and microbial biotransformation of dietary flavan-3-ols and the bioactivity of their metabolites. Food \& Function. 2010, 1, 233-253.

[10] Fernández-Millán, E., Ramos, S., Alvarez, C., Bravo, L., et al., Microbial phenolic metabolites improve glucose-stimulated insulin secretion and protect pancreatic beta 
cells against tert-butylhydroperoxide-induced toxicity via ERKs and PKC pathways. Food Chem Toxicol. 2014, 66, 245-253.

[11] Ahmad, F., Khalid, P., Khan, M. M., Rastogi, A. K., Kidwai, J. R., Insulin like activity in (-) epicatechin. Acta Diabetol Lat. 1989, 26, 291-300.

[12] Cordero-Herrera, I., Martín, M. A., Bravo, L., Goya, L., Ramos, S., Cocoa flavonoids improve insulin signalling and modulate glucose production via AKT and AMPK in HepG2 cells. Mol Nutr Food Res. 2013, 57, 974-985.

[13] Quine, S. D., Raghu, P. S., Effects of (-)-epicatechin, a flavonoid on lipid peroxidation and antioxidants in streptozotocin-induced diabetic liver, kidney and heart. Pharmacol Rep. 2005, 57, 610-615.

[14] Verzelloni, E., Pellacani, C., Tagliazucchi, D., Tagliaferri, S., et al., Antiglycative and neuroprotective activity of colon-derived polyphenol catabolites. Mol Nutr Food Res. 2011, 55, S35-S43.

[15] Vazquez-Prieto, M. A., Bettaieb, A., Haj, F. G., Fraga, C. G., Oteiza, P. I., (-)Epicatechin prevents $\mathrm{TNF} \alpha$-induced activation of signaling cascades involved in inflammation and insulin sensitivity in 3T3-L1 adipocytes. Arch Biochem Biophys. 2012, 527, 113-118.

[16] Cordero-Herrera, I., Martín, M. A., Goya, L., Ramos, S., Cocoa flavonoids attenuate high glucose-induced insulin signalling blockade and modulate glucose uptake and production in human HepG2 cells. Food Chem Toxicol. 2014, 64, 10-19.

[17] Igarashi, K., Honma, K., Yoshinari, O., Nanjo, F., Hara, Y., Effects of dietary catechins on glucose tolerance, blood pressure and oxidative status in Goto-Kakizaki rats. J Nutr Sci Vitaminol. 2007, 53, 496-500. 
[18] Kim, M. J., Ryu, G. R., Chung, J. S., Sim, S. S., et al., Protective effects of epicatechin against the toxic effects of streptozotocin on rat pancreatic islets: in vivo and in vitro Pancreas. 2003, 26, 292-299.

[19] Cordero-Herrera, I., Martín, M. A., Goya, L., Ramos, S., Cocoa flavonoids protect hepatic cells against high glucose-induced oxidative stress. Relevance of MAPKs. Mol Nutr Food Res. 2015, 59, 597-609.

[20] Blodgett, A. B., Kothinti, R. K., Kamyshko, I., Petering, D. H., et al., A fluorescence method for measurement of glucose transport in kidney cells. Diabetes Technol Ther. 2011, 13, 743-751.

[21] Drozak, J., Doroszewska, R., Chodnicka, K., Winiarska, K., Bryla, J., Contribution of L-3,4-dihydroxyphenylalanine metabolism to the inhibition of gluconeogenesis in rabbit kidney-cortex tubules. Int J Biochem Cell Biol. 2005, 37, 1269-1280.

[22] Nowak, G., Schnellmann, R. G., Improved culture conditions stimulate gluconeogenesis in primary cultures of renal proximal tubule cells. Am J Physiol. 1995, 268, C1053-C1061.

[23] Gatica, R., Bertinat, R., Silva, P., Carpio, D., et al., Altered expression and localization of the insulin receptor in proximal tubule cells from human and rat diabetic kidney. J Cell Biochem. 2012, 114, 639-649.

[24] Tiwari, S., Singh, R. S., Li, L., Tsukerman, S., et al., Deletion of the insulin receptor in the proximal tubule promotes hyperglycemia. J Am Soc Nephrol. 2013, 24, $1209-1214$.

[25] Whiteman, E. L., Cho, H., Birnbaum, M. J., Role of Akt/protein kinase B in metabolism. TRENDS Endocrinol Metab. 2002, 13, 444-451.

[26] Marzban, L., Rahimian, R., Brownsey, R. W., McNeill, J. H., Mechanisms by which bis(maltolato)oxovanadium(IV) normalizes phosphoenolpyruvate carboxykinase 
and glucose-6-phosphatase expression in streptozotocin-diabetic rats in vivo. Endocrinology. 2002, 143, 4636-4645.

[27] Mudaliar, S., Polidori, D., Zambrowicz, B., Henry, R. R., Sodium-glucose cotransporter inhibitors: effects on renal and intestinal glucose transport from bench to bedside. Diabetes Care. 2015, 38, 2344-2353.

[28] Jiang, M., Wang, Q., Karasawa, T., Koo, J. W., et al., Sodium-glucose transporter2 (SGLT2; SLC5A2) enhances cellular uptake of aminoglycosides. PLoS One. 2014 9, e108941.

[29] Norton, L., Shannon, C., Fourcaudot, M., Hu, C., et al., Sodium-glucose (SGLT) and glucose (GLUT) transporter expression in the kidney of type 2 diabetic subjects. Diabetes Obes Metab. 2017, doi: 10.1111/dom.13003.

[30] Vinson, J. A., Proch, J., Bose, P., Muchler, S., et al., Chocolate is a powerful ex vivo and in vitro antioxidant, antiatherosclerotic agent in an animal model, and a significant contributor to antioxidants in the European and American diets. J Agric Food Chem. 2006, 54, 8071-8076.

[31] Pérez-Vizcaíno, F., Bishop-Bailley, D., Lodi, F., Duarte, J., et al., The flavonoid quercetin induces apoptosis and inhibits JNK activation in intimal vascular smooth muscle cells. Biochem Biophys Res Comm. 2006, 346, 919-925.

[32] Kroon, P. A., Clifford, M. N., Crozier, A., Day, A. J., et al., How should we assess the effects of exposure to dietary polyphenols in vitro? Am J Clin Nutr. 2004, 80, 15-21. [33] Blaschek, W., Natural products as lead compounds for sodium glucose cotransporter (SGLT) inhibitors. Planta Med. 2017, doi: 10.1055/s-0043-106050.

[34] Panchapakesan, U., Pegg, K., Gross, S., Komala, M. G., et al., Effects of SGLT2 inhibition in human kidney proximal tubular cells-renoprotection in diabetic nephropathy? PLoS One. 2013, 8, e54442. doi: 54410.51371/journal.pone.0054442. 
[35] Anand, P., Murali, K. Y., Tandon, V., Murthy, P. S., Chandra, R., Insulinotropic effect of cinnamaldehyde on transcriptional regulation of pyruvate kinase, phosphoenolpyruvate carboxykinase, and GLUT4 translocation in experimental diabetic rats. Chem Biol Interact. 2010, 186, 72-81.

[36] Winiarska, K., Grabowski, M., Rogacki, M. K., Inhibition of renal gluconeogenesis contributes to hypoglycaemic action of NADPH oxidase inhibitor, apocynin. Chem Biol Interact. 2011, 189, 119-126.

[37] Cordero-Herrera, I., Martín, M. A., Escrivá, F., Álvarez, C., et al., Cocoa-rich diet ameliorates hepatic insulin resistance by modulating insulin signaling and glucose homeostasis in Zucker diabetic fatty rats. J Nutr Biochem. 2015, 26, 704-712.

[38] Diaz-Gerevini, G. T., Repossi, G., Dain, A., Tarres, M. C., et al., Beneficial action of resveratrol: How and why? Nutrition. 206, 32, 174-178.

[39] Nyane, N. A., Tlaila, T. B., Malefane, T. G., Ndwandwe, D. E., Owira, P. M. O., Metformin-like antidiabetic, cardio-protective and non-glycemic effects of naringenin: Molecular and pharmacological insights. Eur J Pharmacol. 2017, 803, 103-111.

[40] Yang, C. S., Zhang, J., Zhang, L., Huang, J., Wang, Y., Mechanisms of body weight reduction and metabolic syndrome alleviation by tea. Mol Nutr Food Res. 2016, $60,160-174$.

[41] Huang, C.-N., Wang, C.-J., Yang, Y.-S., Lin, C.-L., Peng, C.-H., Hibiscus sabdariffa polyphenols prevent palmitate-induced renal epithelial mesenchymal transition by alleviating dipeptidyl peptidase-4-mediated insulin resistance. Food \& Function. 2016, 7, 475-482.

[42] Hu, Q.-H., Zhang, X., Pan, Y., Li, Y.-C., Kong, L.-D., Allopurinol, quercetin and rutin ameliorate renal NLRP3 inflammasome activation and lipid accumulation in fructose-fed rats. Biochem Pharmacol. 2012, 84, 113-125. 
[43] Montagut, G., Bladé, C., Blay, M., Fernández-Larrea, J., et al., Effects of a grape seed procyanidin extract (GSPE) on insulin resistance. J Nutr Biochem. 2010, 21, 961967.

[44] Mariappan, M. M., Prasad, S., D'Silva, K., Cedillo, E., et al., Activation of glycogen synthase kinase $3 \beta$ ameliorates diabetes-induced kidney injury. J Biol Chem. 2014, 289, 35363-35375.

[45] Ghezzi, C., Wright, E. M., Regulation of the human Na+-dependent glucose cotransporter hSGLT2. Am J Physiol Cell Physiol. 2012, 303, C348-C354.

[46] Ferrannini, E., Muscelli, E., Frascerra, S., Baldi, S., et al., Metabolic response to sodium-glucose cotransporter 2 inhibition in type 2 diabetic patients. J Clin Invest. $2014,124,499-508$.

[47] Klover, P. J., Mooney, R. A., Hepatocytes: critical for glucose homeostasis. Int J Biochem Cell Biol. 2004, 36, 753-758.

[48] Prasad, R. C., Herzog, B., Boone, B., Sims, L., Waltner-Law, M., An extract of Syzygium aromaticum represses genes encoding hepatic gluconeogenic enzymes. $J$ Ethnopharmacol. 2005, 96, 295-301.

[49] Bettaieb, A., Vazquez-Prieto, M. A., Rodriguez-Lanzi, C., Miatello, R. M., et al., ()-Epicatechin mitigates high-fructoseassociated insulin resistance by modulating redox signaling and endoplasmic reticulum stress. Free Radic Biol Med. 2014, 72, 247-256. 


\section{Legends to figures}

Figure 1. Effect of EC and DHBA on SGLT-2 and GLUT-2 levels in NRK-52E cells after $24 \mathrm{~h}$ of treatment. (A) Bands of representative experiments. Percentage data of (B) SGLT-2, and (C) GLUT-2 relative to the control condition (means $\pm \mathrm{SD}, \mathrm{n}=9-12$ ). Equal loading of Western blots was ensured by $\beta$-actin. No significant differences were found for $\mathrm{C}$ versus $\mathrm{EC}$, and $\mathrm{C}$ versus DHBA $(P<0.05)$.

Figure 2. Effect of EC and DHBA on levels of PEPCK in NRK-52E cells after $24 \mathrm{~h}$ of incubation. (A) Bands of representative experiments. (B) Densitometric quantification of PEPCK. Values are expressed as a percentage relative to the untreated control condition and are means $\pm \mathrm{SD}, \mathrm{n}=6-8$. Equal loading of Western blots was ensured by $\beta$-actin. (a) $P<0.05$, C versus EC; (b) $P<0.05, \mathrm{C}$ versus DHBA.

Figure 3. Effect of EC and DHBA on phosphorylated and total levels of IR and IRS-1 in NRK-52E cells after $24 \mathrm{~h}$ of treatment. (A) Bands of representative experiments. Densitometric quantification of (B) p-IR and total IR, and (C) p-IRS-1 and total IRS-1. Protein extracts were subjected to immunoprecipitation with the anti-phospho-tyrosine (P-Tyr) antibody. The resulting immunocomplexes were analysed by Western blot with the anti-IR or IRS-1 antibody. Values are expressed as a percentage relative to the control condition (means $\pm \mathrm{SD}, \mathrm{n}=7-10$ ). Equal loading of Western blots was ensured by $\beta$-actin. (a) $P<0.05$, C versus EC; (b) $P<0.05, C$ versus DHBA. Different styles of letters (normal and italics) have been used for each parameter depicted within the same graph. 
Figure 4. Effect of EC and DHBA on levels of phosphorylated and total AKT, GSK3 and GS in NRK-52E cells. (A) Bands of representative experiments. Percentage data of (B) p-(Ser473)-AKT/AKT, (C) p-(Ser 21/9)-GSK3/GSK3 and (D) p-(Ser641)-GS/GS ratios relative to controls. Values are expressed as a percentage relative to the control condition and are means $\pm \mathrm{SD}, \mathrm{n}=6-8$. Equal loading of Western blots was ensured by $\beta$ actin. (a) $P<0.05$, C versus EC; (b) $P<0.05$, C versus DHBA.

Figure 5. Effect of EC and DHBA and the selective inhibitor LY (LY294002) on levels of PEPCK and phosphorylated and total AKT, and glucose production. NRK-52E cells were incubated in the presence or absence of $20 \mu \mathrm{M} \mathrm{LY}$ for $1 \mathrm{~h}$ and later with $10 \mu \mathrm{M} \mathrm{EC}$ or $20 \mu \mathrm{M}$ DHBA for 24 h. (A) Bands of representative experiments. Percentage data of (B) PEPCK, and (C) p-(Ser473)-AKT/AKT relative to the control condition (means \pm $\mathrm{SD}, \mathrm{n}=8-11$ ). Equal loading of Western blots was ensured by $\beta$-actin. (D) Glucose production was expressed as percent of control are means \pm SD of 10-15 different samples per condition. (a) $P<0.05, \mathrm{C}$ versus EC; (b) $P<0.05, \mathrm{C}$ versus DHBA; (c) $P<0.05, \mathrm{C}$ versus LY.

Figure 6. Effect of EC and DHBA and the SGLT-2 inhibitor phlorizin (P) on glucose uptake. NRK-52E cells were incubated in the presence or absence of $0.5 \mathrm{mM}$ P for $1 \mathrm{~h}$ and later with $10 \mu \mathrm{M}$ EC or $20 \mu \mathrm{M}$ DHBA. Glucose uptake was expressed as percent of control are means \pm SD of 8 -14 different samples per condition. (a) $P<0.05$, C versus EC; (b) $P<0.05$, C versus DHBA; (c) $P<0.05$, C versus $\mathrm{P}$. 
Table 1. Effect on glucose uptake and glucose production of EC, DHBA, DHPAA, HPPA and VA calculated as percent of the relative increase or decrease over the control values. Data are means \pm SD of $8-12$ different samples per condition. (a) $P<0.05$, C versus EC; (b) $P<0.05$, C versus DHBA.

\begin{tabular}{|c|c|c|}
\hline & 2-NBDG uptake $\%$ of controls) & Glucose production (\% of controls) \\
\hline C & $100.4 \pm 5.8$ & $100.0 \pm 4.7$ \\
1 & & \\
5 & $95.2 \pm 11.03$ & $94.0 \pm 10.07$ \\
10 & $110.7 \pm 8.0$ & $82.5 \pm 7.1$ \\
20 & $124.4 \pm 13.1^{\mathrm{a}}$ & $64.0 \pm 12.3^{\mathrm{a}}$ \\
\hline DHBA $(\mu \mathrm{M})$ & $140.0 \pm 10.8^{\mathrm{a}}$ & $59.7 \pm 8.2^{\mathrm{a}}$ \\
1 & & $101.6 \pm 4.8$ \\
5 & $93.4 \pm 5.5$ & $97.4 \pm 8.2$ \\
10 & $98.6 \pm 10.7$ & $96.7 \pm 6.4$ \\
20 & $100.5 \pm 12.5$ & $72.3 \pm 8.5^{\mathrm{b}}$ \\
\hline DHPAA $(\mu \mathrm{M})$ & $117.7 \pm 6.6^{\mathrm{b}}$ & \\
\hline
\end{tabular}




\begin{tabular}{|c|c|c|}
\hline 1 & $99.8 \pm 10.1$ & $108.6 \pm 11.3$ \\
5 & $94.8 \pm 10.3$ & $108.9 \pm 6.9$ \\
10 & $106.3 \pm 7.5$ & $110.4 \pm 5.8$ \\
20 & $104.1 \pm 5.7$ & $107.7 \pm 8.7$ \\
\hline HPPA $(\mu \mathrm{M})$ & $91.0 \pm 4.2$ & \\
1 & $92.1 \pm 4.7$ & $96.4 \pm 8.7$ \\
5 & $92.5 \pm 6.9$ & $99.6 \pm 5.8$ \\
10 & $102.6 \pm 5.8$ & $107.2 \pm 9.7$ \\
20 & & $105.5 \pm 6.0$ \\
\hline VA $(\mu \mathrm{M})$ & $97.0 \pm 9.5$ & $104.9 \pm 9.7$ \\
1 & $98.4 \pm 8.9$ & $111.0 \pm 10.4$ \\
5 & $94.3 \pm 7.9$ & $99.0 \pm 7.8$ \\
10 & $92.5 \pm 8.2$ & $93.5 \pm 8.4$ \\
\hline 20 & & \\
\hline
\end{tabular}


Figure 1

A

SGLT-2

GLUT-2

$\beta$-actin
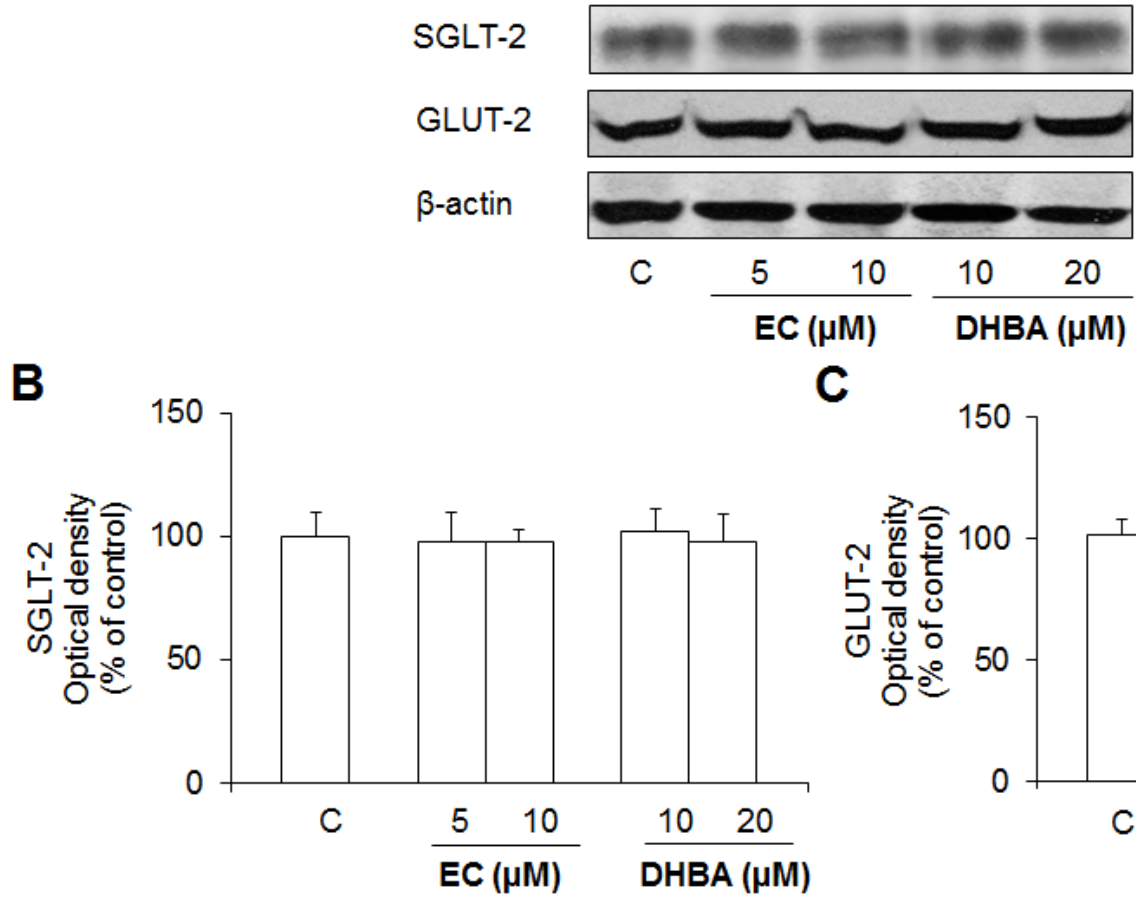

C

150

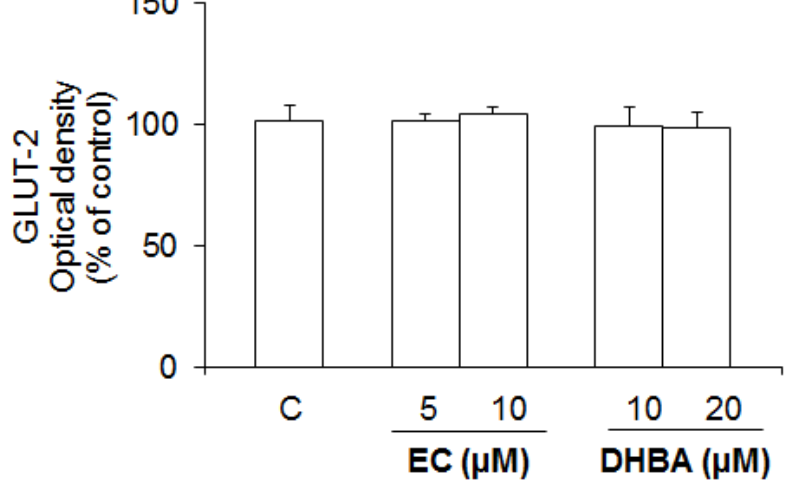


Figure 2 
A

PEPCK

$\beta$-actin

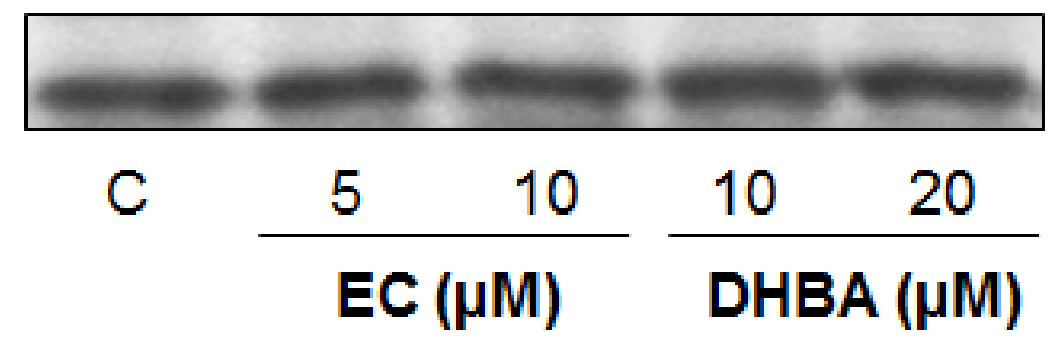

B

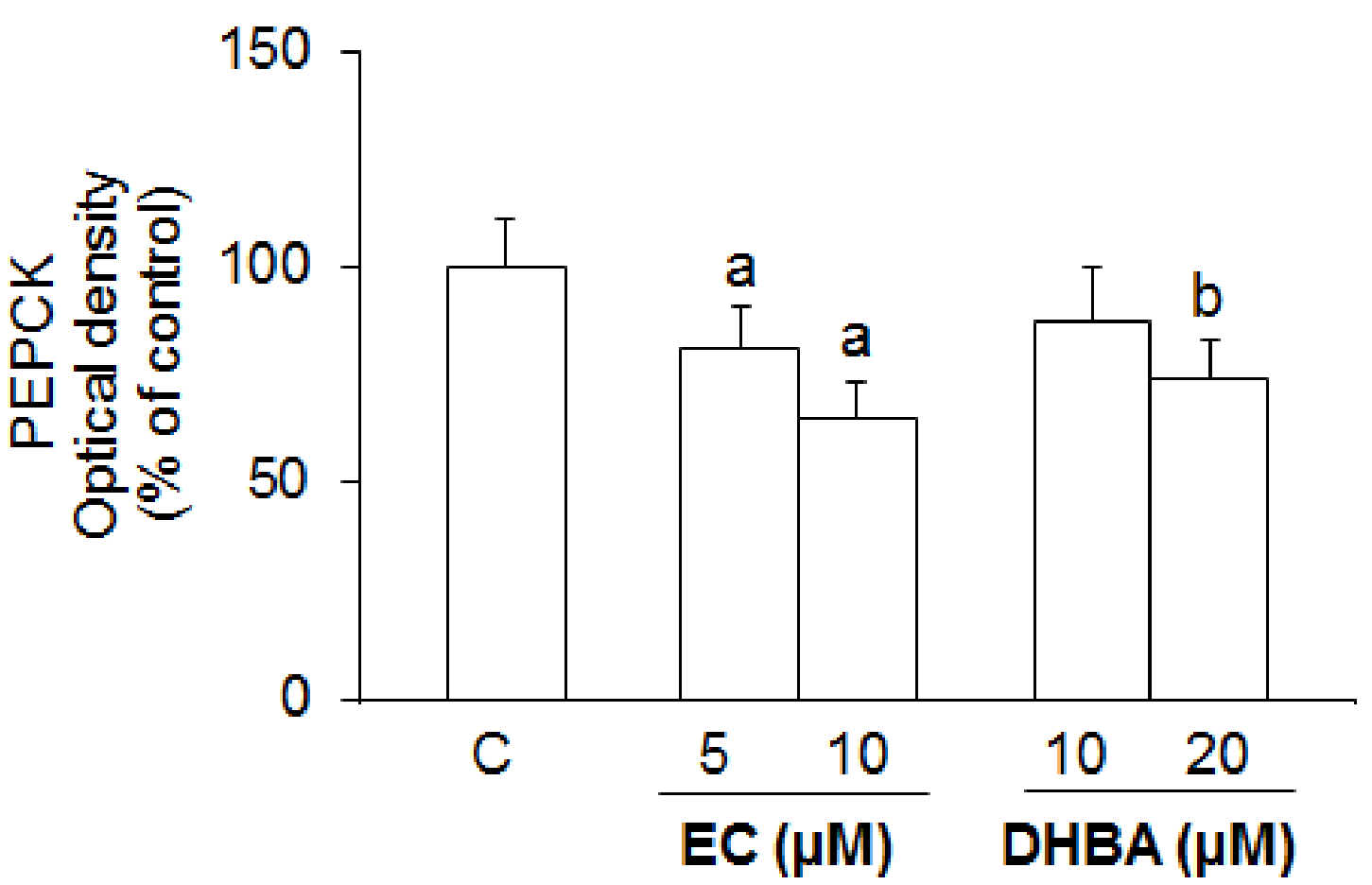


Figure 3

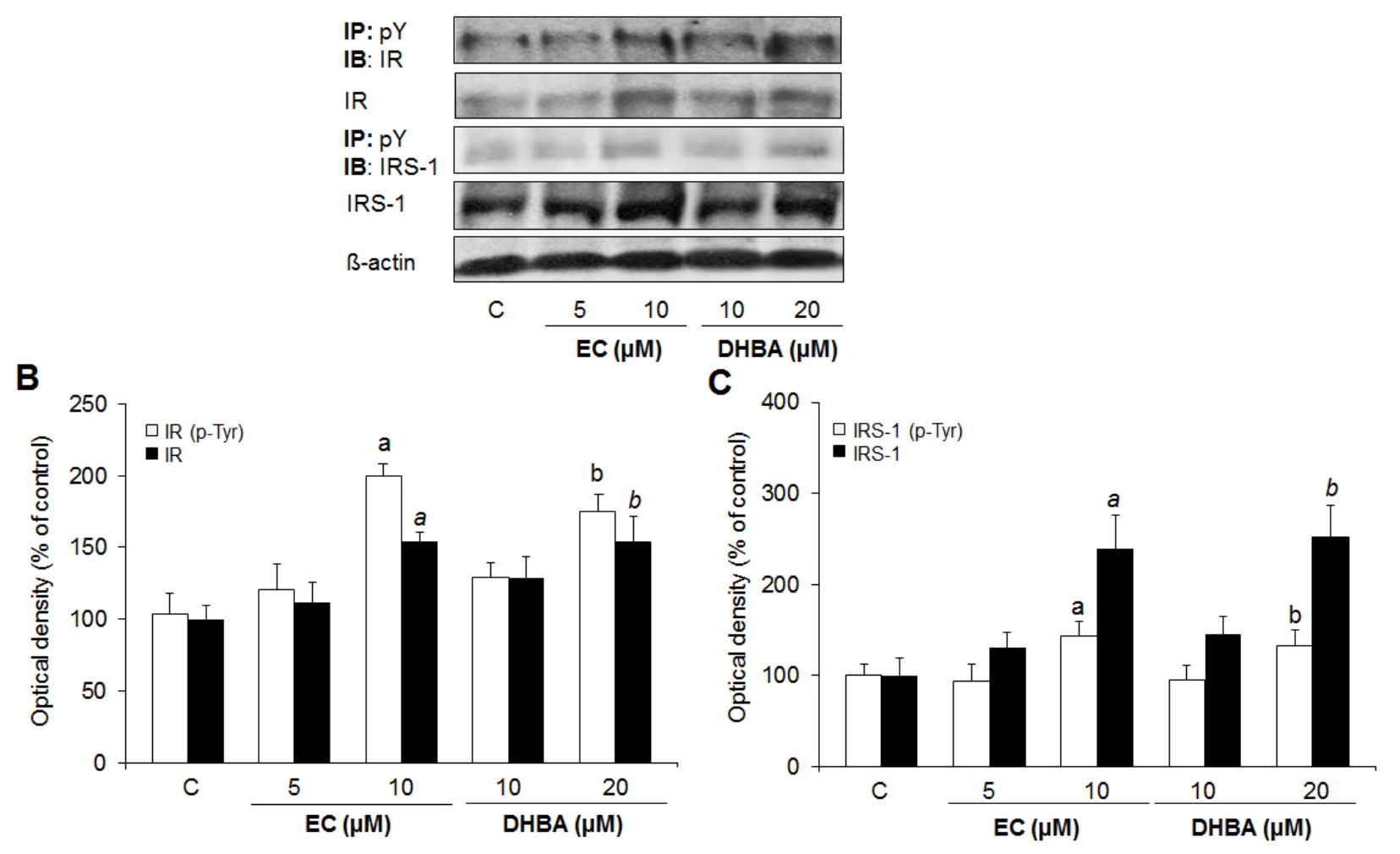




\section{Figure 4}

A
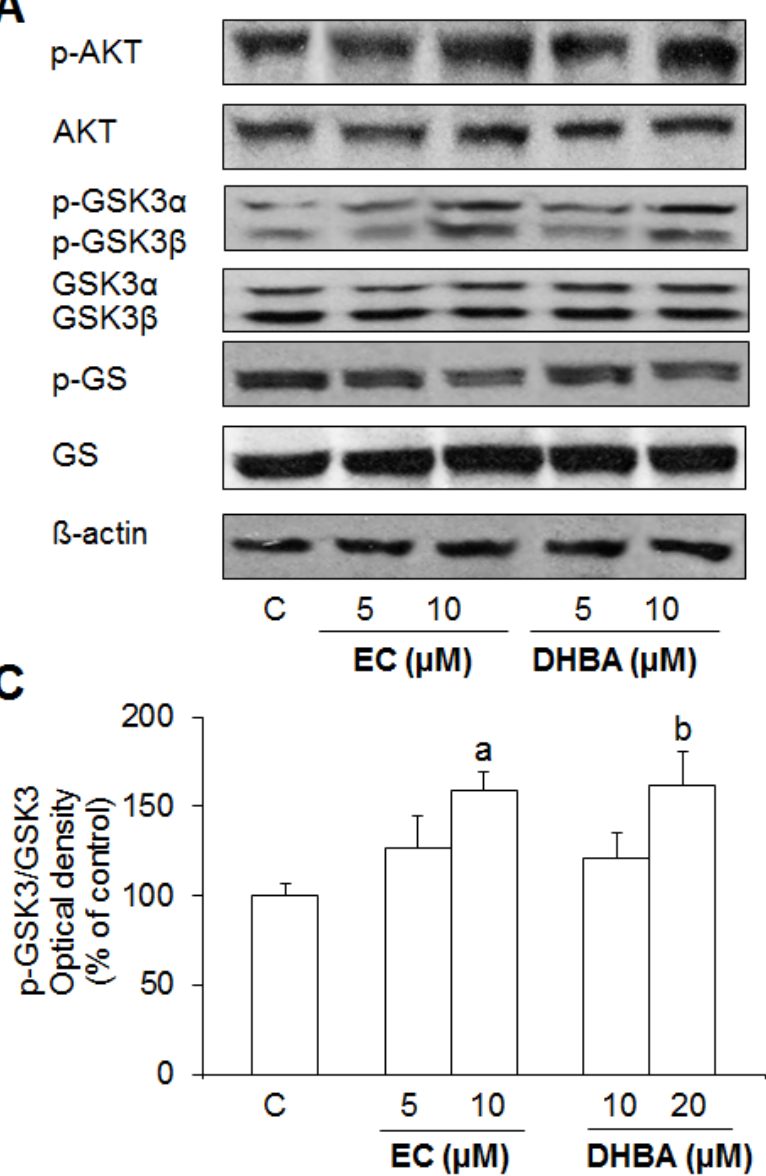

B

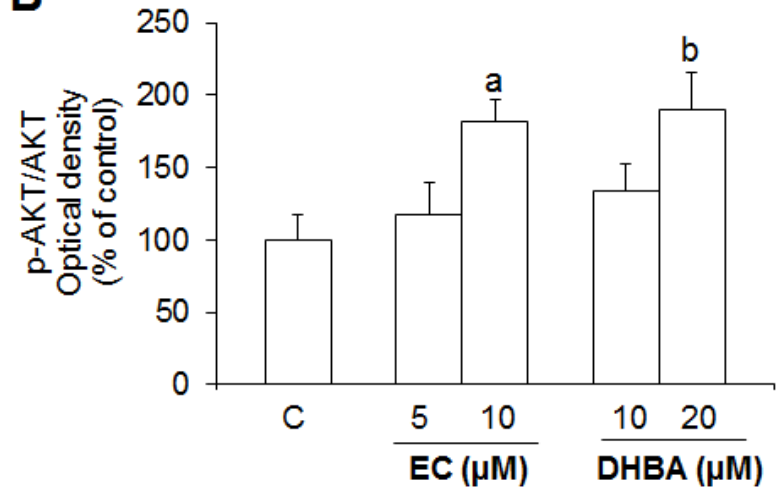

D

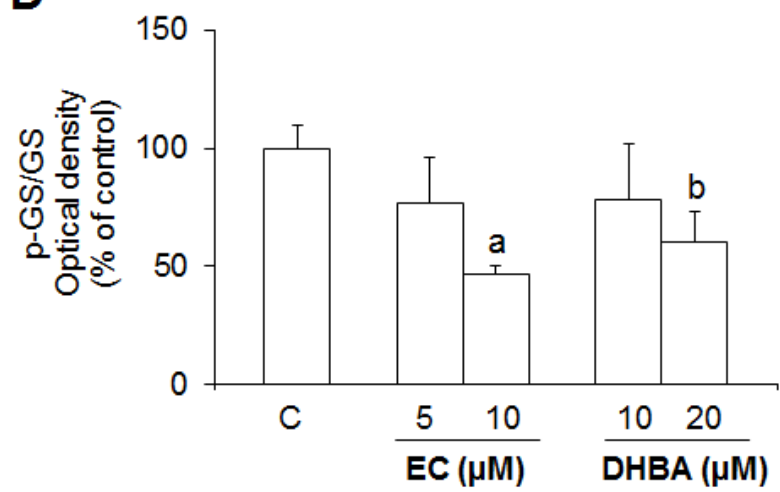


Figure 5
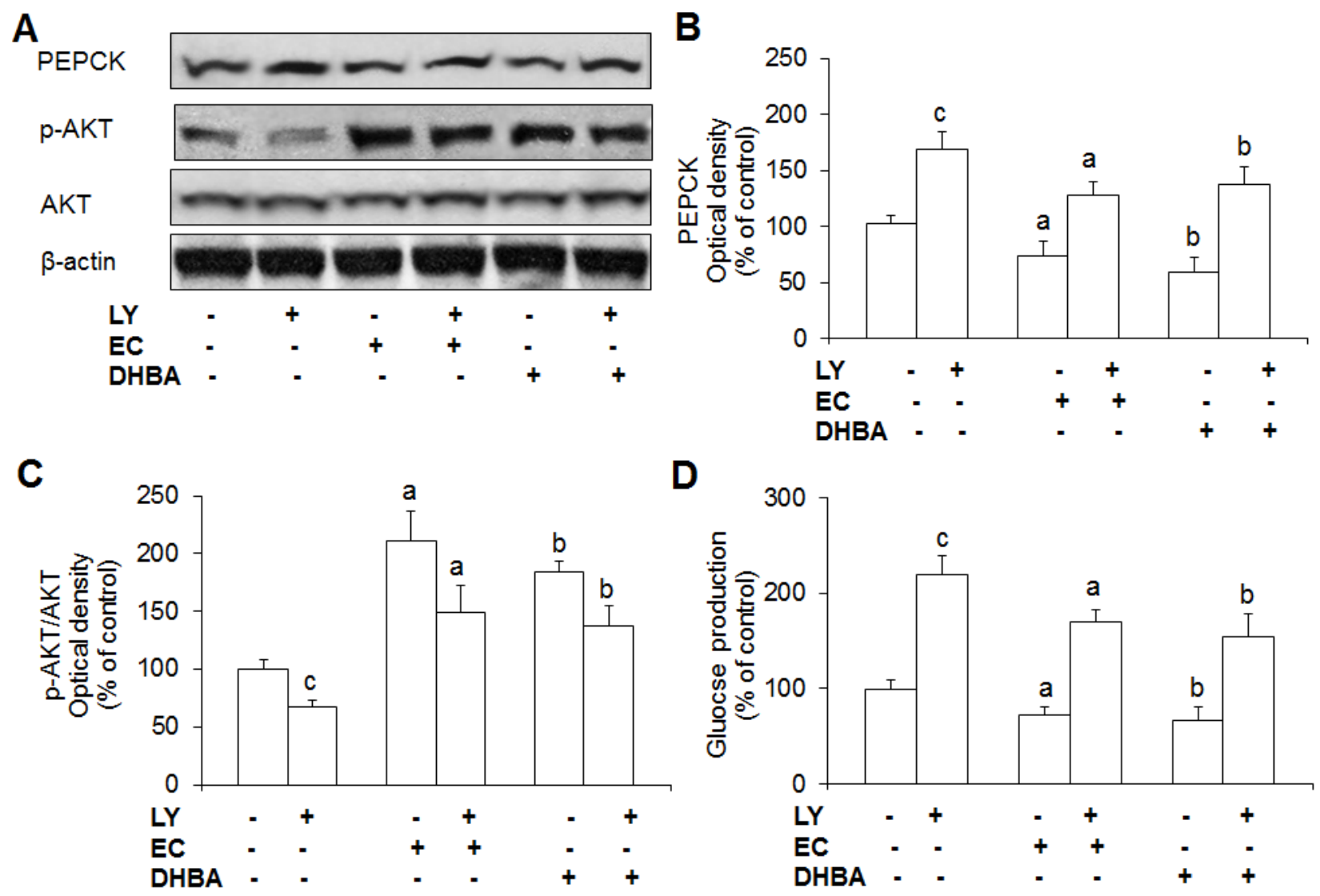
Figure 6

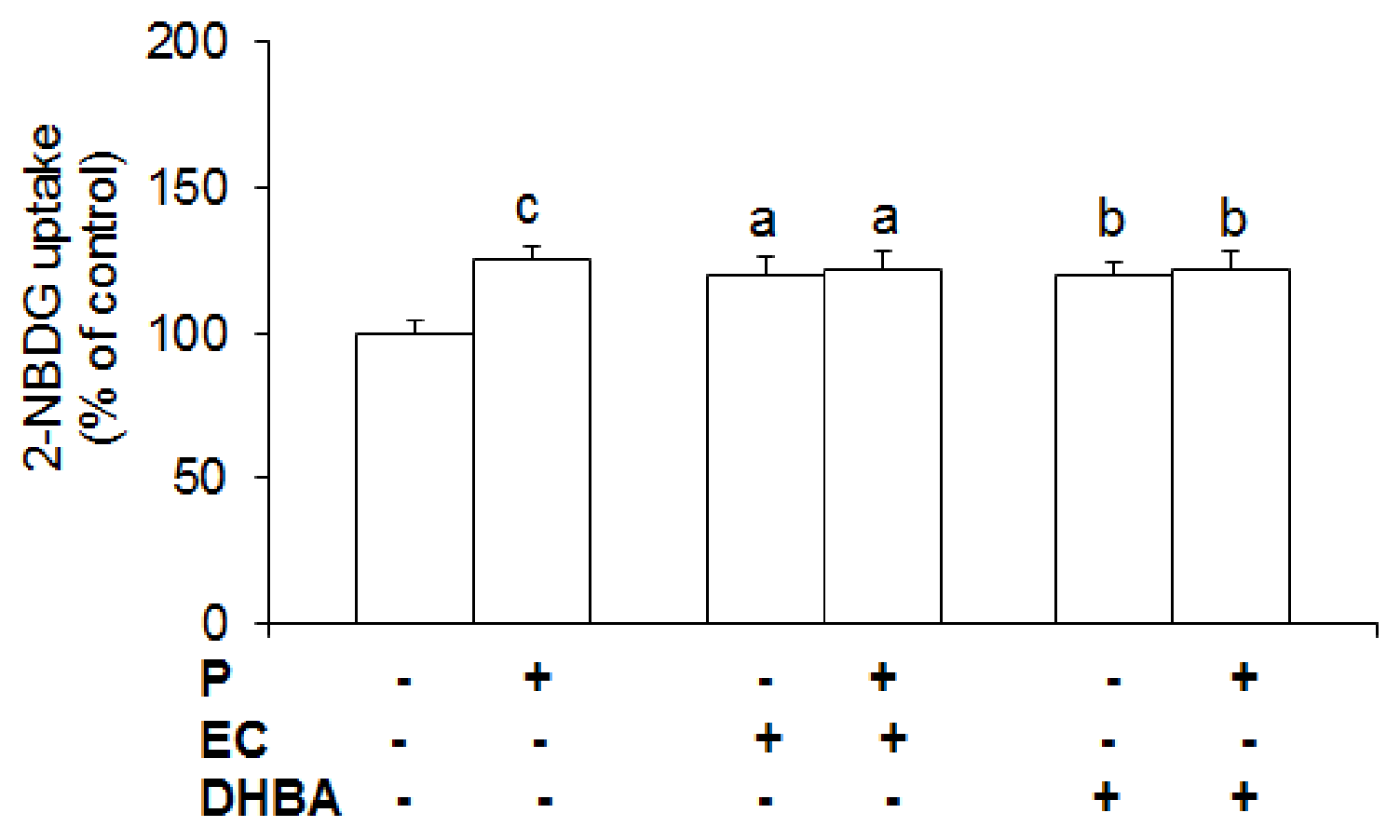


Supplementary Table 1. Effects on cell viability of EC, DHBA, DHPAA, HPPA and VA. Cell viability was determined as relative percent of Crystal Violet stained control cells (\% of viable cells). Data represent means \pm SD of 8-10 samples. No differences were found after incubating the cells with any treatment in comparison to control cells $(P<0.05)$.

\begin{tabular}{|c|c|c|c|c|c|}
\hline & EC & DHBA & DHPAA & HPPA & VA \\
\hline C & \multicolumn{5}{|c|}{$100.0 \pm 7.1$} \\
\hline \multicolumn{6}{|l|}{$\mu \mathbf{M}$} \\
\hline 1 & $91.5 \pm 6.9$ & $104.3 \pm 9.2$ & $105.3 \pm 7.7$ & $107.1 \pm 8.8$ & $105.3 \pm 7.5$ \\
\hline 5 & $95.2 \pm 6.8$ & $105.2 \pm 4.0$ & $107.8 \pm 5.9$ & $109.7 \pm 8.8$ & $109.3 \pm 5.6$ \\
\hline 10 & $100.0 \pm 8.5$ & $110.6 \pm 10.0$ & $112.0 \pm 7.9$ & $112.3 \pm 7.1$ & $106.9 \pm 8.5$ \\
\hline 20 & $104.1 \pm 8.6$ & $109.9 \pm 6.9$ & $106.2 \pm 9.8$ & $109.5 \pm 8.8$ & $101.4 \pm 7.8$ \\
\hline 40 & $103.0 \pm 9.3$ & $113.9 \pm 7.5$ & $105.8 \pm 6.8$ & $107.0 \pm 9.9$ & $103.4 \pm 7.9$ \\
\hline 50 & $99.0 \pm 7.7$ & $105.9 \pm 9.6$ & $107.2 \pm 6.6$ & $110.7 \pm 5.2$ & $108.0 \pm 8.7$ \\
\hline 100 & $97.5 \pm 8.8$ & $108.5 \pm 9.0$ & $105.5 \pm 6.7$ & $106.5 \pm 7.8$ & $108.7 \pm 8.8$ \\
\hline
\end{tabular}




\section{Supplementary Figure 1}

A

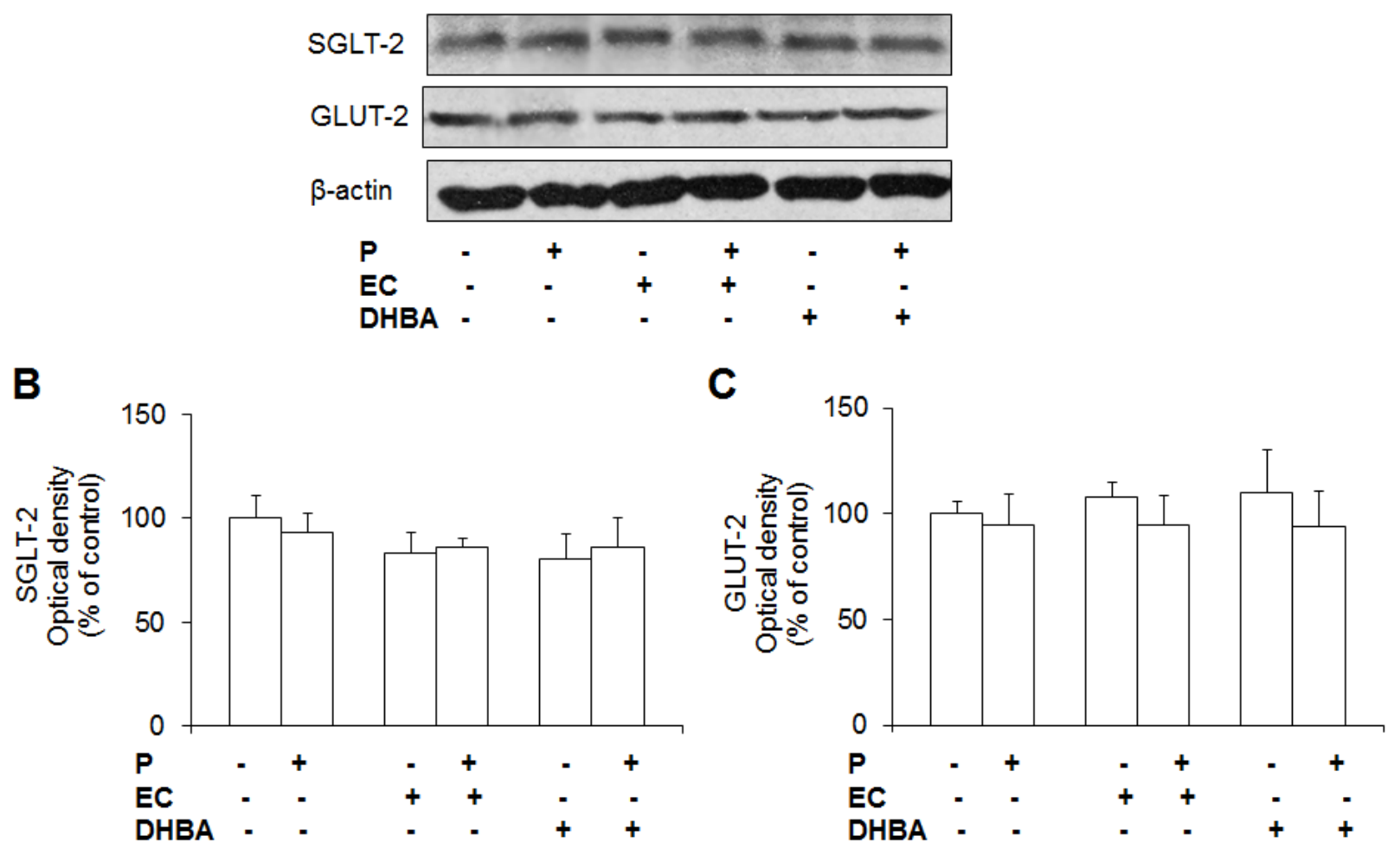

Supplementary Figure 1. Effect of EC and DHBA and the SGLT-2 inhibitor phlorizin (P) on levels of SGLT-2 and GLUT-2. NRK-52E cells were incubated in the presence or absence of $0.5 \mathrm{mM}$ P for $1 \mathrm{~h}$ and later with $10 \mu \mathrm{M}$ EC or $20 \mu \mathrm{M}$ DHBA. (A) Bands of representative experiments. Densitometric quantification of (B) SGLT-2 levels and (C) GLUT-2. Values are expressed as a percentage relative to the control condition and are means $\pm \mathrm{SD}, \mathrm{n}=6-10$. Equal loading of Western blots was ensured by $\beta$-actin. No significant differences were found when compared control cells with EC-, DHBA- and P-treated cells $(P<0.05)$. 